\title{
0 processo de Bolonha: da harmonização à sintonização, passando pela convergência
}

\author{
Alberto Amaral*
}

\section{Resumo}

A mobilidade dos estudantes, a empregabilidade dos diplomados e a comparabilidade dos cursos apareceram como pedras de toque no Processo de Bolonha. Todavia, a mobilidade dos estudantes na Europa está restringida a uma pequena percentagem do número total de alunos matriculados e cada vez mais o movimento neoliberal diminui a responsabilidade social dos governos em relação aos empregos. Não obstante a existência de governos que exaltam o acordo de Bolonha, o processo chega, agora, numa fase crítica, correndo o risco de tornar-se um entrave para a inovação, para a diversidade e até para as ricas características culturais dos Estados membros. No presente texto, são relatados fatos e apresentados argumentos que evidenciam o momento vital pelo qual está passando o Processo de Bolonha e a crua realidade de dificuldades e perigos para os sistemas nacionais de educação superior europeus.

Palavras-chave: Educação Superior. Processo de Bolonha. Espaço Europeu de Ensino Superior.

\section{No princípio era a harmonização ${ }^{1}$}

Os primeiros passos do processo de Bolonha foram dados na Universidade da Sorbonne, em 25 de maio de 1998, 30 anos depois do famoso Maio universitário, que não era então celebrado, e 800 anos depois da fundação da Universidade de Paris, esta sim a efeméride a comemorar. Para abrilhantar a cerimónia,

\author{
Recebido: 19/05/2015 - Aprovado: 22/08/2015 \\ http://dx.doi.org/10.5335/rep.v22i2.5563
}

\begin{abstract}
Doutor em Química Quântica pela Universidade de Cambridge, no Reino Unido. Foi reitor da Universidade do Porto, Portugal, de 1985 a 1998; de 1998-2008 dirigiu o Centro de Investigação de Políticas do Ensino Superior (CIPES), um dos principais núcleos de investigação da educação superior da Europa. Desde 2008 até o presente momento preside a Agência de Avaliação e Acreditação do Ensino Superior (A3ES) que tem como missão garantir a qualidade da educação superior em Portugal e viabilizar a inserção do país no sistema europeu de garantia da qualidade. É membro do conselho editorial de algumas das mais importantes revistas científicas sobre educação e avaliação, tais como Quality Assurance in Education; Studies in Learning, Evaluation, Innovation and Development e Higher Education Dynamics. Foi membro do Conselho de reitores das instituições universitárias de Portugal, participou de várias comissões públicas e interministeriais de trabalho e investigações sobre educação superior em diferentes países e foi membro do corpo executivo da Associação das Universidades Europeias. Tem diversos títulos e condecorações por suas contribuições para o mundo acadêmico em diferentes países e é autor de reconhecidos livros e publicações científicas sobre os sistemas de educação superior.
\end{abstract}


em substituição à tentativa frustrada de atribuir o doutoramento honoris causa a alguns Ministros da Educação Europeus, optou-se pela assinatura do que viria a ser conhecido como "Declaração da Sorbonne". Essa declaração, assinada pelos Ministros da Educação da Alemanha, França, Itália e Reino Unido, tem por título Harmonização da arquitetura do sistema de ensino superior Europeu e propõe a organização do ensino superior em dois ciclos, o primeiro, ao nível da pré-graduação e reconhecido internacionalmente como nível apropriado de qualificação (supõe-se que para o mercado de trabalho, embora o texto não seja explícito), e o segundo, ao nível da pós-graduação, com opção entre uma variante curta, tipo mestrado, e uma variante longa, tipo doutoramento.

Os observadores mais benevolentes viram na declaração uma reafirmação política da necessidade de criar um espaço Europeu de ensino superior capaz de apoiar os mercados económico, comercial e financeiro em desenvolvimento nos últimos anos no seio da União Europeia, e de aumentar a mobilidade de mão de obra qualificada dentro da União, condição para o aumento da sua competitividade num mundo em globalização crescente. Os observadores mais cépticos - ou talvez menos bem intencionados - viram na declaração uma espécie de Viagra ou de suplemento vitamínico de três ministros com dificuldades em impor reformas nacionais, pelo que usaram a alavanca da União em apoio das suas teses.

Porém, se há alguma discordância na interpretação do "porquê?" da Sorbonne, pelo contrário existe unanimidade em reconhecer que a forma como a declaração foi apresentada gerou diversos mal-entendidos (BARBLAN, 1999).

O primeiro mal-entendido resultou do facto de escassas semanas antes da declaração da Sorbonne ter sido publicado em França o relatório Attali (1998) - curiosamente intitulado "Para um Modelo Europeu do Ensino Superior" - no qual se procura compatibilizar as estruturas de ensino das Universidades francesas e das Grandes Écoles, propondo uma arquitetura de 3-5-8 anos que se pode associar ao primeiro ciclo pré-graduado e aos ciclos curto e longo de graduação da Declaração da Sorbonne. Apesar de na Declaração nada ser dito quanto à duração dos ciclos, muitos comentadores assumiram a fórmula mágica de 3-5-8 como uma forma de apresentar o essencial da Declaração da Sorbonne, o que ocasionou reações extremamente negativas de todos os que viram no modelo uma imposição externa e uma ingerência "de Bruxelas" nos sistemas nacionais de ensino superior.

O segundo mal-entendido resultou da utilização do termo harmonização. Apesar da afirmação corrente de que um dos maiores bens da UE reside na multiplicidade das culturas e na diversidade dos sistemas de ensino superior dos Estados Membros, e que a harmonização da formação para profissões específicas não significa uniformização, a tradição centralizadora da burocracia de Bruxelas sempre deixou pouco à vontade as universidades, pese embora a venerável proteção do 
princípio da subsidiariedade (AMARAL, 2001). São conhecidas algumas normas de carácter uniformizador da burocracia Europeia, como as relativas à forma e tamanho dos pepinos, ao tamanho das laranjas, à capacidade mínima dos depósitos dos autoclismos, ou à qualidade da areia dos parques infantis, normas estas que produzem arrepios em qualquer académico. Algumas citações permitem ilustrar este problema; do Memorando sobre o Ensino Superior (EUROPEAN COMMISSION, 1991, p. 7): “... considera-se provável que um dos efeitos práticos da diretiva (reconhecimento de diplomas) será estimular movimentos de convergência na formação para profissões específicas."

E, ainda:

[...] a questão crítica é a de saber se é possível dar a este sistema, enorme e diversificado, um enfoque Europeu para que promova objectivos comunitários, entre os quais se incluem a partilha da riqueza cultural da Europa entre os cidadãos Europeus e a promoção da identidade e um compromisso Europeu que irá coexistir com as alianças regionais e nacionais... (EUROPEAN COMMISSION, 1991, p. 14)

Do relatório do IRDAC (1994, p. 29),

As diferenças significativas entre os sistemas Europeus de educação (em termos de números, de qualidade e de organização) podem ser uma fonte de enriquecimento cultural e educativo e, em boa verdade, uma fonte de inovação.

[...] ao encorajar-se um movimento no sentido de uma terminologia comum, por meio da cooperação interinstitucional e da aceitação gradual da compatibilidade dos objectivos educativos nacionais, pode tornar-se uma realidade a convergência, gradual e em resposta à demanda externa, dos produtos educativos da Europa - baseada, em primeiro lugar em padrões mínimos mutuamente aceites e no reconhecimento recíproco.

Estas citações produzem alguma inquietação devido à anterior tradição de uniformização da burocracia de Bruxelas; ora a utilização do termo harmonização despertou imediatamente a visão de curricula uniformes em todo o espaço da União. Este sentimento negativo surgiu, embora na Declaração nada se refira quanto à harmonização de conteúdos, curricula ou métodos de ensino. Apenas se utiliza o termo harmonização no título da Declaração, em relação à "arquitetura do sistema de ensino superior Europeu" e no seu texto em relação à "estrutura global de graus e ciclos".

O terceiro mal-entendido resultou do facto de a Declaração ter sido assinada pelos quatro maiores países da União que depois convidaram os outros estado membros a associarem-se, o que despertou desconfianças de uma Europa a duas velocidades, liderada pelos quatro membros de maior peso, subalternizando os países de menor dimensão.

Finalmente, apesar das baterias apontadas a Bruxelas, a verdade é que se tratou de uma iniciativa de países, ao arrepio do estabelecido no Tratado da União 
e marginalizando a Comissão Europeia a quem, em princípio, estão cometidas as tarefas de redigir as propostas para promover a integração Europeia e, numa visão menos benevolente, poderá ser considerada como a imposição de interesses nacionais sob a capa do interesse Europeu (ver nota 2).

\section{Da harmonização à convergência}

Na sequência da celeuma causada pela declaração da Sorbonne e pela série de mal-entendidos que lhe foram associados, foi decidido promover a elaboração de uma nova declaração que viria a ser assinada por 29 Ministros Europeus em Bolonha, a 19 de Junho de 1999. Na nova declaração "harmonização" passou a ser uma palavra proscrita devido à sua associação com temores de uniformização dos sistemas nacionais, sendo substituída por "convergência”. Curiosamente, no texto da Declaração de Bolonha apresentam-se como objectivos “... estabelecer a área Europeia de ensino superior e promover o sistema Europeu de ensino superior em todo o mundo." Como muito bem refere a European Association for International Education $^{2}$ (EAIE), num comentário emitido em Amsterdão, em Novembro de 1999, a utilização das expressões "área Europeia" e "sistema Europeu” na mesma frase causa confusão quanto aos objectivos e a diferença não é meramente semântica, é uma diferença crucial. Como é evidente o estabelecimento de "um sistema Europeu de ensino superior" tem porventura conotações ainda mais uniformizadoras do que o termo maldito "harmonização". Ora, embora se saiba que os Ministros produzem documentos políticos e não artigos científicos, era de esperar alguma cautela na elaboração do documento, tanto mais que tinha havido o infeliz precedente da declaração da Sorbonne.

É importante notar que a Declaração de Bolonha não é nem uma diretiva comunitária nem um acordo internacional no sentido convencional, ou seja, dela não resulta uma obrigação ou imposição legal. A declaração traduz um compromisso comum assumido por um conjunto de governos nacionais em relação ao princípio da "Europeização" do ensino superior, por meio de uma cooperação crescente entre instituições (ver referência da nota 3). Os objectivos principais referidos na declaração são os seguintes:

- promoção da mobilidade dos cidadãos;

- promoção da empregabilidade e do desenvolvimento geral do Continente;

- aumento da competitividade internacional do Sistema Europeu de Ensino Superior;

- participação dos países europeus num processo de cooperação tendo em vista os seguintes seis objectivos instrumentais: 
- adopção de um sistema de graus legível e comparável;

- adopção de um sistema baseado em dois ciclos, pré-graduado e graduado;

- estabelecimento de um sistema de créditos - tal como no sistema ECTS - como forma apropriada de promover a mobilidade dos estudantes;

- promoção da mobilidade por remoção dos obstáculos à livre movimentação de alunos, professores, investigadores e pessoal administrativo;

- promoção da cooperação Europeia na garantia da qualidade;

- promoção da dimensão Europeia no ensino superior.

Assinada por 29 ministros, removido o espinho da harmonização, dadas garantias de que não se pretende uniformizar os sistemas nacionais de ensino superior e dados os objectivos louváveis expressos na Declaração parece que existem razões para a adesão em massa das universidades. No entanto, isso não tem acontecido por razões que iremos tentar expor mais tarde.

É interessante recordar que a CRE (Association of European Universities), tendo ficado de fora da redação da Declaração de Bolonha conseguiu, como prémio de consolação, efetuar uma reunião no dia anterior ao da assinatura da declaração, do que resultou um relatório que o seu presidente, Dr. Kenneth Edwards, apresentou aos ministros da educação ${ }^{3}$. A estratégia da CRE comportou grandes riscos - como é evidente, o relatório não poderia ter qualquer influência sobre o texto da declaração e, caso esta fosse prejudicial para as universidades, poderia dar a impressão de que as universidades, reunidas no dia anterior, tinham cooperado no processo. É ainda curioso notar que no relatório da CRE se fala imprudentemente "na aceitação de um mecanismo externo de acreditação" que os ministros na sua sabedoria ignoraram, referindo apenas a promoção da cooperação Europeia na garantia da qualidade tendo em vista o desenvolvimento de critérios e metodologias comparáveis. Iremos ver que este se tornará um problema recorrente no desenvolvimento do processo de Bolonha.

$\mathrm{Na}$ sequência da reunião de Bolonha foi estabelecida uma metodologia para evitar que a Declaração caísse no esquecimento, convocando uma nova reunião de Ministros em Praga, para dois anos depois e marcando deveres para casa; ao mesmo tempo, a $\mathrm{CRE}^{4}$ ganhou assento à mesa das negociações, benesse concedida igualmente aos estudantes que tinham manifestado de forma clara o seu desagrado por serem ignorados no processo ${ }^{5}$.

O período que decorreu até à reunião de Praga foi frenético e cheio de iniciativas. Realizaram-se três encontros internacionais sobre "Sistemas de Acumulação e Transferência de Créditos" - em Leiria -, sobre o Grau de Bacharel - em Helsín- 
quia - e sobre "Ensino Transnacional" - em Malmö, destinados a fornecer material para o relatório a apresentar aos Ministros. Porém, apesar de todo o entusiasmo e boa vontade dos organizadores, as conclusões dos encontros ficaram bastante aquém das expectativas.

O Seminário sobre Créditos ${ }^{6}$ concluiu que as tarefas a enfrentar são enormes, que um sistema de acumulação e transferência de créditos é desejável e que poderia ter como ponto de partida o ECTS e, ainda, que é difícil discutir créditos e níveis de referência num contexto abstracto pelo que o sistema terá de ser desenvolvido por áreas, sendo de apoiar o projeto piloto Tuning?.

O Seminário sobre o grau de bacharel $^{8}$ resultou numa acesa discussão entre os que advogam a convergência para uma estrutura Bacharel-Mestre-Doutorado e aqueles que se opõem a um processo estrito de convergência. Para dificultar mais as coisas, recorde-se que a Declaração de Bolonha defende que o grau correspondente ao primeiro ciclo deve ser relevante para o mercado de trabalho Europeu como nível apropriado de qualificação. O problema é que em determinadas áreas como Medicina, Engenharia ou Arquitetura (para citar apenas algumas das mais evidentes) o exercício profissional não é compatível com um primeiro ciclo relativamente curto que, a existir, será irrelevante para o mercado de trabalho. Assim, para além de um primeiro grau com a duração de 3 ou 4 anos, ou um grau integrado de 5 anos conduzindo ao mestrado, surge ainda a hipótese de algumas áreas serem excluídas da estrutura de Bolonha, ou de serem criados graus intermédios (diploma de mobilidade pré-graduada) sem relevância para o mercado de trabalho, mas permitindo o acesso a uma fase complementar de estudos.

Mas um outro problema começou a emergir no caso dos países com um sistema binário de universidades e politécnicos. Aqui o Seminário conclui, timidamente, que:

é importante reconhecer que os graus com nível de bacharel, frequentemente referidos como primeiros graus, podem ser obtidos tanto em universidades tradicionais como em instituições de ensino superior com orientação vocacional. Os programas de estudo conducentes a um grau podem, e na verdade devem ter orientações diferentes e vários perfis para responder a uma diversidade de necessidades individuais, académicas e do mercado de trabalho (Seminar on Bachelor-Level Degrees, 2001, p. 2).

O Seminário sobre Ensino Transnacional ${ }^{9}$ considerou positivo o Código de Boa Prática proposto pela UNESCO e reconheceu a necessidade de os governos terem uma política concertada em relação à avaliação de qualidade e políticas de reconhecimento do ensino transnacional.

Também a EUA (em transição da CRE) esteve ativa, tendo decidido prestar atenção particular à questão da acreditação, embora de uma forma condenável. De facto, a EUA decidiu proceder a um estudo sobre a possibilidade de ser criado um 
sistema de acreditação dos cursos recorrendo a um projeto intitulado "Towards accreditation schemes for higher education in Europe?", financiado pela UE ao abrigo do Programa Sócrates. Foram realizados três encontros em Paris (18-19 de Setembro de 2000), em Viena (8-9 de Novembro de 2000) e em Bruxelas (7 de Dezembro de 2000). No primeiro encontro, apenas estiveram presentes dois reitores, sendo os restantes 11 elementos pessoas ligadas a agências de avaliação ou funcionários do Secretariado da CRE; no segundo encontro estiveram presentes cinco reitores ou ex-reitores e 20 elementos ligados a atividades de avaliação ou funcionários administrativos; na última reunião estiveram presentes 10 elementos, apenas um dos quais era um reitor.

Foi em seguida realizado um "Seminário de Validação" que teve lugar em Lisboa, de 8 a 10 de Fevereiro de 2001, no qual participaram 187 pessoas, das quais 66\% representavam universidades membros da CRE. Este Seminário tinha por objectivo aprovar uma moção para ser apresentada na Convenção de Salamanca, da qual por sua vez sairia uma recomendação para os Ministros reunidos em Praga. Enquanto se esperava a apresentação de diversas alternativas para um debate crítico, o que se viu foi uma montagem em que só intervieram adeptos dos sistemas de acreditação. Para quem assistiu ao seminário só é possível uma conclusão: as universidades sentiram-se de algum modo manipuladas e rejeitaram claramente o estabelecimento de um sistema de acreditação Europeu, manifestando ainda as maiores dúvidas sobre o valor acrescentado de processos de acreditação em termos de melhoria da qualidade - em suma, estragou-se a marcha triunfal da acreditação até Salamanca.

É lamentável que o comunicado final do Seminário não refletisse o que se passou em Lisboa, sendo habilmente redigido para permitir uma ressurreição da acreditação em Salamanca. De facto, no comunicado final ${ }^{10}$ pode ler-se: "Os líderes do ensino presentes em Lisboa/Oeiras desejam continuar a discussão sobre a implementação de esquemas viáveis para a garantia da qualidade na Europa, incluindo a validação de procedimentos de acreditação..."

Em Salamanca repetiram-se os tiques antidemocráticos da reunião de Lisboa. $\mathrm{Na}$ Convenção das Instituições de Ensino Superior Europeu foi lançado, de novo, o tema da acreditação o qual, mais uma vez, gerou uma forte reação contrária por parte da maioria das instituições presentes. Este facto foi registado pela imprensa internacional presente ${ }^{11} \mathrm{e}$, no relatório elaborado por Pedro Lourtie ${ }^{12}$ para os Ministros da Educação reunidos em Praga em Maio de 2001, pode ler-se: 
A questão de quem é responsável por definir os padrões de referência mostrou ser delicada e controversa, especialmente se vista ao nível Europeu. Ao lado dos que acreditam firmemente na acreditação, mesmo a nível Europeu, estão os que temem que padrões Europeus impostos do exterior serão inadequados para a realidade ou sistema nacional e constituem uma restrição sobre a capacidade intelectual para inovar (Lourtie 2001, p. 16).

No entanto, no comunicado ${ }^{13}$ da Convenção de Salamanca para a reunião de Praga pode ler-se: "O caminho para o futuro será o de implementar mecanismos ao nível Europeu para a aceitação mútua dos resultados da garantia da qualidade, sendo a 'acreditação uma das opções possíveis."

Felizmente, os Ministros da Educação reunidos em Praga tiveram a percepção das dificuldades políticas de um mecanismo Europeu de acreditação e esse tema foi cuidadosamente excluído do seu comunicado final, o qual refere apenas a necessidade de uma maior coerência dos mecanismos de avaliação/acreditação utilizados em cada Estado membro. O comunicado apoia as conclusões do encontro de Helsínquia no que procura salvaguardar em relação aos sistemas binários e reafirma que o ensino superior deve ser considerado um bem público e é e será uma responsabilidade pública. Finalmente, foi marcada nova reunião em Berlim para dois anos depois, ou seja, para o segundo semestre de 2003.

\section{Da convergência à sintonização}

Na passagem da Sorbonne para Bologna e com o exorcismo do termo "harmonização" poderia pensar-se que estavam definitivamente afastados os perigos de uma uniformização dos sistemas nacionais Europeus. Mas será que isto é verdade e que podermos estar descansados?

Curiosamente, o perigo de uma diminuição da diversidade dos sistemas de ensino superior Europeus - até há bem pouco considerada como uma vantagem competitiva da Europa - como consequência dos processos de transparência e comparabilidade dos graus é bastante anterior a Bolonha. Já em 1994 o IRDAC (1994, p. 29), embora reconhecendo que "as diferenças significativas dos sistemas de educação Europeus (em termos de números, qualidade e organização) podem ser uma fonte de enriquecimento cultural e, na verdade, uma fonte de inovação" concorda em que o aumento da transparência pode levar à convergência dos produtos resultante da demanda (IRDAC, 1994, p. 3).

Isto levanta uma questão fundamental: pode a diversidade ser protegida pelo princípio da subsidiariedade? Note-se que o IRDAC já em 1994 afirmava que “... além disso, o tratado de Maastricht criou uma base firme para intervenção a nível Europeu, ao fazer uma referência explícita à melhoria da qualidade do ensino e da 
formação". Será que a qualidade - ou ainda pior, a acreditação - vão ser o cavalo de Troia do ensino superior? É possível evitar que se crie um sistema Europeu de acreditação que contribua para diminuir a diversidade dos sistemas Europeus?

Há, infelizmente, algumas indicações de que o processo de Bolonha poderá ultrapassar os limites fixados na declaração de intenções que evita cuidadosamente 0 uso do termo harmonização. Por exemplo, nas minutas de uma reunião da Direção da CRE pode ler-se:

A CRE, como parte da sua conferência sobre cenários de acreditação para a Europa, devia analisar se as áreas científicas mais importantes ensinadas no ensino superior Europeu se poderão construir em torno de um curriculum cerne considerado fundamental ao nível Europeu, um pouco segundo o modelo do que está a ser feito pelo EFMD para os estudos de gestão. A EUA poderia tornar-se o foco para esse debate, no caso de as associações definirem uma plataforma para a qualidade (CRE, 2000).

Isto é muito interessante. Não há muito tempo houve um movimento de afastamento dos sistemas de controlo pelo Estado - no qual os curricula eram definidos centralmente pelos burocratas dos Ministérios ou pelos académicos mais conservadores (nos casos em que prevalecia a oligarquia académica) - por sistemas de supervisão pelo Estado, com aumento da autonomia universitária. O que vemos agora é a própria CRE/EUA, uma associação de universidades, a explorar a possibilidade de existência de "curricula cerne" Europeus, mais uniformes e definidos centralmente (por uma nova oligarquia académica com uma dimensão Europeia?)!

Em 4 de Maio de 2001 foi lançado o projeto 'Tuning Educational Structrures in Europe' (http://odur.let.rug.nl/TuningProject/background.asp) com apoio financeiro da Comissão. O projeto 'Tuning' procurou:

- 'Sintonizar' as estruturas educativas Europeias, ajudando, assim, ao desenvolvimento de uma Área Europeia de Ensino Superior.

- Iniciar um debate sobre a natureza e a importância de competências gerais e específicas, envolvendo todos os stakeholders, incluindo académicos, diplomados e empregadores.

- Identificar e permutar informação sobre pontos de referência comuns, conteúdos curriculares, resultados de aprendizagem e métodos de ensino, aprendizagem e avaliação.

- Melhorar a cooperação e a colaboração Europeias no desenvolvimento da qualidade, eficácia e transparência do ensino superior Europeu, examinando os créditos ECTS e outros mecanismos apropriados para favorecer o progresso.

O projeto 'Tuning' faz uma declaração de princípios cautelar: não procura 
[...] desenvolver nenhuma espécie de curricula Europeus unificados, prescritivos ou finais; ou criar um sistema rígido de especificações para restringir ou orientar o conteúdo, o modo de apresentação ou a natureza do ensino superior Europeu; ou acabar com a riqueza da diversidade do ensino Europeu, restringir a independência dos académicos e especialistas, ou prejudicar a autonomia académica local e nacional (Tuning, 2002, p. 3).

Andrée Sursock (2002, p. 3) é bastante mais cautelosa quanto às possíveis consequências do Tuning:

Há, porém, uma tentação à qual recomendo com insistência aos governos para resistirem: que os resultados de tais discussões não acabem como um protótipo para avaliações. O risco existente é o de se impedir a mudança em nome dos padrões e que, uma vez estes codificados, se desatualizem sem qualquer esperança em relação ao estado da arte do conhecimento.

$\mathrm{Na}$ verdade, bem podemos perguntar se o 'Tuning' não irá abrir a porta a algum tipo de 'harmonização forte', ou mesmo 'uniformidade'. Dois exemplos ajudarão a compreender esta observação. O primeiro exemplo é a Química, para a qual o Tuning define 8 módulos obrigatórios (Física, Matemática, Química Geral, Química Analítica, Química Inorgânica, Química Orgânica, Química Física e Química Biológica), cada um com um número mínimo de créditos atribuídos, a que se segue uma recomendação sobre os créditos dos módulos semiopcionais. Quanto aos resultados da aquisição de conhecimento definem-se 14 domínios que vão desde os estados da matéria à mecânica quântica, da termodinâmica à cinética incluindo a catálise, dos compostos alifáticos, aromáticos, heterocíclicos e organometálicos às macromoléculas, da síntese em química orgânica à química analítica, etc. (http:// www.deusto-publicaciones.es/deusto/pdfs/tuning/tuning15.pdf). Quando isto se combina com recomendações sobre a acreditação é óbvio que se corre o risco de fortes pressões no sentido de um aumento da uniformidade.

O segundo exemplo é o da Matemática. O 'Tuning' para Matemática (http:// www.unideusto.org/tuningeu/images/stories/key_documents/tuningmathematicsfinal.pdf, p. 30) recomenda que a acreditação dos cursos inclua o cumprimento de um conjunto de requisitos por parte das universidades em relação ao currículo cerne, o que se faz verificando uma lista de conteúdos, uma lista de capacidades adquiridas e o nível de domínio dos conceitos. Diz-se, também, de forma clara, que:

[...] cremos que grandes desvios do padrão (tal como a estrutura 3+1) devem ser fundamentados por meio de exigências ao nível das entradas, ou outros factores específicos do curso que possam ser avaliados por uma acreditação externa. De outro modo, esses cursos correm o risco de não beneficiar de um reconhecimento automático Europeu baseado numa estrutura comum, mesmo que possam ser cursos meritórios de ensino superior (Tuning 2012, p. 30).

Mais uma vez é evidente que este tipo de recomendações irá aumentar as pressões para que as instituições adoptem uma estrutura mais uniforme dos cursos. 
Estes dois exemplos ilustram o risco que as universidades correm de serem apanhadas numa malha burocrática que terá um efeito muito negativo, quer sobre a diversidade da oferta, quer sobre a autonomia institucional. Nas palavras Andrée Sursock (2002, p. 3), do que precisamos é de "criar uma estrutura comum de graus e definir níveis indicativos para o $\mathrm{BA} / \mathrm{MA}$, mas de tal modo que não venha a sufocar a aprendizagem, os alunos e os professores".

Isto demonstra, também, que todos os cuidados a lidar com o processo de Bolonha são poucos já que existem, obviamente, diversos interesses, muito bem colocados nos centros de decisão de Bruxelas, que poderão criar um movimento indesejável de uniformização.

\section{Qual o peso das razões invocadas a propósito de Bolonha e quais os riscos?}

Em boa verdade, as três grandes razões que são invocadas para justificar o processo de Bolonha não são de modo algum convincentes.

A primeira razão apontada é a do emprego: o processo de Bolonha é necessário para permitir que os Europeus consigam emprego em qualquer país da UE. Ora, que eu saiba, as grandes empresas internacionais empregam e despedem funcionários com grande à vontade, indo buscar a mão de obra onde ela é melhor e, se possível, mais barata. Hoje importam-se peritos informáticos da Índia, os ingleses vão buscar médicos e enfermeiros às antigas colónias e muitas empresas tem contratado engenheiros em Portugal ou na Irlanda, por períodos probatórios de seis a doze meses e despedindo-os ao fim desse tempo, se não corresponderem ao esperado. E nada disto precisa da convergência dos planos de estudo. A única exceção será, eventualmente o emprego público, mas não vejo facilmente um país a contratar não nacionais para o preenchimento dos lugares dos serviços públicos, a não ser em casos excepcionais (por exemplo, enfermeiros em Portugal ou no Reino Unido). Portanto, não me parece que a questão da empregabilidade, neste sentido, tenha grande significado em termos do processo de Bolonha.

Depois fala-se que a segunda questão é a da mobilidade dos alunos. No entanto, os alunos são cada vez menos móveis. Mesmo dentro das fronteiras nacionais, a mobilidade dos alunos tem estado a diminuir de forma assustadora. Há exemplos óbvios, como o Reino Unido, onde o aluno que terminava o ensino secundário se mudava tradicionalmente para longe da casa dos pais. Ora, assim que o Estado começou a fazer contas aos custos de andar a deslocar os alunos num ensino superior massificado, mudou rapidamente de ideias e os alunos, no Reino Unido, estão hoje cada vez mais localizados. Principalmente, porque o Estado, ao mesmo tempo que cortou no orçamento das universidades, substituiu as bolsas por empréstimos e, na- 
turalmente, o aluno faz contas à vida e pensa quanto é que vai ficar a dever quando terminar o seu curso se optar pelo luxo de se mudar para fora da casa dos seus pais.

A própria União Europeia, depois do proclamado êxito do Erasmus (embora nunca se tenha sequer aproximado das metas fixadas em termos de números de alunos que se deslocaram a outros sistemas de ensino) já passou cuidadosamente os custos da mobilidade para os diversos Estados membros. Portanto, a mobilidade é muito mais um instrumento retórico do que um instrumento efetivo para a criação de um espírito Europeu. Por isso, também não me parece que a mobilidade seja um factor tão grande, ou forte, que nos obrigue a andar para aqui a convergir.

E, em terceiro lugar, há os neoliberais que dizem ser necessário criar um mercado Europeu para fazer face à concorrência dos americanos. Ora, eu penso que isto é um perfeito disparate, uma vez que quanto mais uniformizado for o mercado Europeu, mais iremos dar azo a que outras instituições, nomeadamente de origem americana ou de carácter privado, venham a instalar-se neste apetecível mercado Europeu convergido.

E há exemplos disso. Recordo que está pendente na World Trade Organization uma proposta dos USA no sentido de se removerem as barreiras ao livre fornecimento de serviços de ensino superior. Os americanos, tendo feito contas às suas exportações e contabilizando como exportações aquilo que cobram em propinas aos alunos estrangeiros, acharam que era uma boa ideia transformar o ensino na mesma coisa que se faz hoje com as bananas ou as batatas e, assim, defender a livre circulação deste tipo de serviços nos diversos países.

Este é, aliás, um processo exemplar que demonstra de forma clara a falta de legitimidade democrática da atuação da Comissão. As universidades tiveram conhecimento da questão da WTO por acaso. A liberalização dos serviços de ensino, pelos vistos, estava a ser negociada pelos ministros da economia à socapa dos ministros da educação. Desenvolveram, então, um grande trabalho de lobbying e, por intermédio das suas organizações representativas (AUCC - Association of Universities and Colleges of Canada, ACE - American Council on Education, USA - European University Association, e CHEA - Council for Higher Education Accreditation dos USA), produziram em 28 de Setembro de 2001 uma declaração conjunta ${ }^{14}$ em que exprimem a sua discordância quanto a possíveis acordos a celebrar no contexto do GATS sobre Serviços de Ensino Superior, ou nas áreas relacionadas de Educação de Adultos e Outros Serviços de Educação.

Mas, curiosamente, acabaram por descobrir que a UE já tinha assumido alguns compromissos nesta matéria, que aparentemente eram do desconhecimento dos $\mathrm{Mi}$ nistros da Educação Europeus que se calhar andavam distraídos com o processo de Bolonha. Também a IAUP (International Association of University Presidents) 
questionou, em 10 de Junho de 2002, o Ministro Dinamarquês da Economia, tendo recebido em 1 de Agosto a espantosa resposta ${ }^{15}$ que transcrevo parcialmente:

Os serviços educativos fazem parte das negociações do GATS. O acordo, porém, exclui explicitamente das negociações o ensino público e, na minha opinião, devemos continuar a excluir os serviços públicos de educação, ao mesmo tempo que se exploram novas oportunidades de mercado para os segmentos do sector de ensino com financiamento privado.

A EU assumiu amplos compromissos no fim do Uruguay Round, liberalizando o acesso ao mercado dos serviços de ensino com financiamento privado, e gostaria de sublinhar que este compromisso não criou de modo algum um desafio aos nossos sistemas educativos públicos na EU. Além disso, os segmentos comerciais do sector educativo despertaram pouco interesse na WTO. Até agora, apenas quatro países, USA, Austrália, Nova Zelândia e Japão, manifestaram interesse em negociar o ensino privado. $\mathrm{O}$ seu interesse foca-se, essencialmente, no ensino terciário, mas também inclui componentes de educação de adultos e de treino para as corporações.

Deixem-me acrescentar que acho extremamente importante que a liberalização do sector educativo seja acompanhada por uma estrutura reguladora conveniente ao nível doméstico. Nada no GATS impede os governos de regularem os serviços quanto à qualidade ou outros desígnios nacionais.

Além disso, o princípio do tratamento nacional do GATS garante que a legislação será aplicada igualmente aos fornecedores públicos e privados em sectores abertos à competição estrangeira.

No sector educativo, o reconhecimento das qualificações e a acreditação constituem os maiores obstáculos ao progresso da internacionalização. Como sabem, estas barreiras são tratadas pelo recurso a acordos de reconhecimento mútuo. O GATS sustenta este trabalho dando aos outros países acesso à negociação para adesão a qualquer acordo deste tipo estabelecido entre dois ou mais países, e assegurando que o reconhecimento é feito numa base não discriminatória (Bendtsen, 2002).

Portanto, eu não vejo uma enorme vantagem no processo de Bolonha, nomeadamente devido aos riscos de perda de diversidade. Aliás, há um artigo muito interessante, escrito nos Estados Unidos por Van Weigel (2000, p. 10-15), em que ele chama a atenção para que as Universidades correm hoje um perigo enorme. Segundo este autor, embora possa parecer alarmista, ele considera que a maioria das instituições educacionais, de todos os tamanhos e feitios, estão, sem perceber, a percorrer um caminho que pode levar à autodestruição para todas, excepto umas poucas.

Este caminho é o da comodificação (mercadorização) da educação; por favor perdoem-me este neologismo, que se refere-se a um processo em que os produtos ou serviços se tornam padronizados, a tal ponto que os seus atributos são praticamente os mesmos. Ora, quando um produto ou um serviço é comodificado, ele pode ser mais facilmente comparado com outros produtos e a competição anda estritamente em torno das questões de custo - e aqui as universidades não poderão competir com grandes iniciativas privadas que apostam muito mais no aspecto do preço do que na qualidade. Portanto, quanto mais semelhante se tornar o que fazemos a nível de ensino superior, provavelmente mais riscos correremos em relação aos riscos da comodificação. 
Outro tema recorrente de Bolonha é, como já foi referido, o da acreditação. Quais são as vantagens e as desvantagens da acreditação dos cursos? Na Conferência da CRE realizada em Utrecht, em 1991, van Vught (1991, p. 61-83) propôs que um sistema Europeu de avaliação da qualidade deveria seguir o modelo do sistema de acreditação dos USA, com o recurso a agências de acreditação múltiplas para evitar "o monopólio burocrático de uma única agência Europeia para o ensino superior". E ele referiu a vantagem de uma situação "tipo-mercado" em que tanto as instituições como as agências têm alguma liberdade de escolha. Neste sistema, as instituições poderão construir "redes de qualidade de instituições com missões semelhantes e acreditadas pelas mesmas agências de acreditação", pondo ênfase em objectivos e padrões específicos.

Os USA são, provavelmente, o país com uma tradição de acreditação mais antiga. Os USA são igualmente apresentados com frequência como o protótipo de um sistema diversificado de ensino superior (1988, p. 31), no qual o mercado desempenha um papel dominante enquanto que o governo federal não intervém na regulação do sistema. Porém, nos USA, a diversidade é principalmente institucional, não programática. $\mathrm{O}$ sistema de ensino superior americano compreende uma enorme diversidade de instituições, desde algumas das melhores universidades de investigação do mundo (as universidades de investigação representam, apenas, $3 \%$ do sistema) até alguns "community colleges" extremamente modestos. Existe um sistema institucional de acreditação, por agências privadas de âmbito regional, onde se utiliza um critério de 'fitness for purpose' que tem em conta a declaração de missão de cada instituição, por forma a proteger esta enorme diversidade, quer em termos de qualidade, quer em termos de dimensão (EL-KHAWAS, 1993). A Fundação Carnegie (1987) afirma que os USA se orgulham da diversidade do seu sistema de ensino superior, formado por uma rica variedade de instituições que servem uma grande diversidade de necessidades.

O sistema Americano de acreditação tem sido objecto de algumas críticas nos últimos anos. David Dill (1996, p. 17-24) escreveu sobre a falta de adequação dos processos correntes e dos padrões de acreditação dos USA e referiu a incapacidade da acreditação voluntária para resolver os problemas dos mecanismos institucionais de garantia de qualidade. Martin Trow partilha esta opinião:

Nos USA, a prestação externa de contas das instituições de ensino superior, principalmente sob a forma de acreditação, tem sido em grande medida irrelevante para a melhoria do ensino superior; em alguns casos, serviu mais para resguardar as instituições de uma monitorização eficaz da sua própria performance educativa do que para a promover; em outros casos, impediu efetivamente as instituições de melhorar. Encoraja as instituições a relatar mais os seus pontos fortes do que os seus falhanços - ou mesmo a ocultar as suas fraquezas e falhanços (1996, p. 316). 
Elaine El-Khawas (1993) relatou alguns pontos fracos tradicionais do sistema de acreditação americano, tal como a forma 'acomodatícia' de julgar uma instituição apenas em termos da sua missão declarada, e a fraca qualidade da evidência apresentada pelas instituições para a acreditação. Isto é consequência da necessidade de reconhecer diferenças de tipo institucional e de missão num sistema diversificado, e é a principal razão que levou Adelman and Silver (1990, p. 2) a considerar que "nestas circunstâncias, nem as entidades de acreditação profissional, nem as entidades de acreditação institucional, podem declarar que desenvolveram medidas imutáveis de qualidade".

Para resolver estas dificuldades, Dill recomenda que a garantia da qualidade deve combinar "um sistema de avaliações de qualidade do ensino e da aprendizagem, de base institucional, combinado com um sistema coordenado regionalmente de auditorias académicas, os quais se reforçam mutuamente" (1996, p. 17-24). Martin Trow considera que o papel das agências exteriores supranacionais, governamentais ou quase-governamentais deverá consistir em "monitorar e encorajar a emergência nas instituições de ensino superior de massas desta cultura [de qualidade, de excelência, que sempre existiu nas grandes instituições de investigação], mas não por meio de avaliações baseadas em critérios uniformes e ligadas ao financiamento" $(1994$, p. 39). Isto corresponde muito mais a uma 'auditoria de qualidade' do que a uma avaliação de qualidade ou uma acreditação (AMARAL; MAGALHÃES, 2004, p. 92). Trow também recomenda que "se transforme a acreditação por avaliações externas da qualidade institucional em auditorias exigentes ao que cada instituição usa como mecanismos de autoavaliação, dos seus próprios procedimentos internos para controlo da qualidade" (1996, p. 316).

Portanto, diversos autores, em relação ao caso dos USA, recomendam que a responsabilidade da criação dos mecanismos necessários para a avaliação e a melhoria da qualidade seja de cada instituição, ficando as atuais seis associações regionais de acreditação com o papel de meta-avaliação ou de auditoria.

Assim, o sistema tradicional de acreditação dos USA está a transformar-se, progressivamente, num sistema de auditoria. A introdução de um uso crescente de auditoria nos tradicionais exercícios de acreditação académica concentrou a atenção na melhoria dos processos de ensino, aprendizagem e avaliação necessários à melhoria da qualidade. A alteração dos padrões de acreditação reduziu o investimento do tempo gasto em atividades geralmente associadas à garantia da qualidade - menor número de relatórios, menor exigência na apresentação de dados - e permitiu que as instituições e os cursos concentrassem energias no desenvolvimento de estratégias de melhoria de um número de atividades. A introdução de acreditações focadas em problemas específicos permitiu que uma instituição ou 
curso dediquem uma atenção especial a uma área como, por exemplo, a melhoria curricular, o ensino à distância ou o ensino profissional numa determinada área.

$\mathrm{Na}$ Europa existe uma enorme diversidade programática (estruturas de graus diferentes, duração diferente dos cursos, diferentes sistemas de acesso, etc.) mas a diversidade institucional é muito menor do que a dos USA. Muitas das instituições de ensino superior americanas não seriam consideradas como tal na Europa. Com o movimento no sentido de um sistema Europeu 'convergido' de ensino superior, a Europa poderá destruir muita da diversidade programática, sem aumentar a diversidade institucional.

Quaisquer que sejam as razões - uma visão tipo Capital Humano do ensino superior como um ingrediente indispensável para a competitividade económica Europeia, ou uma preocupação com as persistentes desigualdades das classes sociais em relação ao acesso ao ensino superior - existe na Europa uma preocupação crescente com sistemas mais inclusivos de ensino superior. Isto significa que as instituições de ensino superior deverão admitir alunos de uma variedade crescente de origens sociais e com uma variedade crescente de necessidades e interesses de aprendizagem. Para corresponder a esta variedade crescente de estudantes, a Europa necessita de ser flexível e de preservar a diversidade de soluções. Sursock (2002, p. 2) considera que, para haver inovação e para desenvolver a criatividade, é necessária uma certa dose de 'ambiguidade construtiva' - defendendo a autonomia institucional - e é necessário "promover um sistema de ensino superior que seja caracterizado pelos três Vs - vibração, vitalidade e variedade":

Se queremos vibração, vitalidade e variedade nas nossas instituições, não deveremos tomar medidas para que os procedimentos de avaliação da qualidade correspondam a estes objectivos? [...] permitindo um certo grau de caos e interdisciplinaridade que promovam a criatividade e a inovação? [...] considerando o seu papel [dos professores] globalmente, em termos das dimensões de ensino, investigação e prestação de serviços, em vez de avaliar separadamente cada aspecto? [...] tendo em conta a sua [dos estudantes] experiência global e avaliando as instituições como um todo, em vez das suas partes constituintes? (2002, p. 3).

Um dos problemas dos sistemas de acreditação (os USA são uma honrosa exceção) reside no facto de, nos casos em que se pretende que a acreditação ande a passo com a melhoria da qualidade, a primeira componente tender rapidamente a colonizar a segunda e predominar nas prioridades das instituições de ensino superior, originando culturas de submissão, diminuição da diversidade e burocracias pesadas e inflexíveis. Recentemente, a CRE procedeu à avaliação de uma agência de acreditação num país do Leste Europeu, tendo recomendado que a avaliação orientada para a melhoria da qualidade devia tornar-se a preocupação fundamental da agência, relegando para um papel secundário as atividades para fins de licenciamento - acreditação baseada em padrões mínimos. 
Tendo em atenção o princípio da subsidiariedade, a responsabilidade pela criação dos mecanismos necessários de qualidade deve permanecer dentro das competências de cada um dos Estados membros, enquanto que a responsabilidade de verificar que esses mecanismos existem em cada Estado pode ser cometida a um nível supranacional (a dimensão Europeia). Ao mesmo tempo (AMARAL, 2001), auditorias institucionais do tipo das desenvolvidas pela CRE/EUA devem ser encorajadas na Europa, sendo o seu objectivo mais focado em dar maior ênfase à verificação de que as instituições têm sistemas próprios de garantia da qualidade do ensino e da aprendizagem que atuam de forma segura e eficaz, ao mesmo tempo que se preserva como característica do sistema de auditorias o seu carácter de apoio à emergência de uma cultura de excelência.

\section{Conclusões gerais}

A mobilidade dos estudantes, a empregabilidade dos diplomados e a comparabilidade dos cursos aparecem como pedras de toque de políticas que visam a convergência dos sistemas nacionais de ensino superior, pelo menos ao nível Europeu. A questão que se levanta é, porém, a da forma como foi estabelecida esta agenda política: resultou de iniciativas nacionais, tendo em conta características nacionais, necessidades nacionais e o grau nacional de desenvolvimento económico e social, ou resultou da definição de uma estratégia de desenvolvimento a nível transnacional? Como é que este movimento no sentido da convergência Europeia ganhou ímpeto? Será que este movimento corresponde a um processo democrático ou é liderado por outro tipo de forças? Esta questão é crucial para compreender o processo de Bolonha.

A mobilidade dos estudantes na Europa está restringida a uma pequena percentagem do número total de alunos matriculados - a despeito de alguns programas de mobilidade financiados pela EU, a percentagem dos alunos que se deslocaram fica vergonhosamente aquém do conseguido no início do século XVII - e é muito pouco provável que esta percentagem venha a aumentar no futuro dados os custos da mobilidade internacional. Significa isto que estamos a ter todo este trabalho por causa de uma pequena minoria de privilegiados? Ou, nas palavras de Guy Neave, "para os de pendor sociológico, a questão é algo diferente É se a arquitetura que a Declaração da Sorbonne revelou e que a reunião de Bolonha confirmou, não está orientada para permitir a emergência de uma Euro-elite e para isso subordina a educação e a formação de massas a este único fim primário?” (2001, p. 185) Ou, de modo ainda mais directo: 
O perigo que a Europa enfrenta não é o espectro de uma Europa de geometria variável ...É antes a possibilidade de uma Europa com um perfil comum de uma sociedade dividida entre os que são móveis, treinados para viver num mundo de salários elevados, alta produtividade e emprego igualmente precário - uma nova elite cuja identidade se baseia totalmente nas sua proezas transnacionais e técnicas - e a maioria dos que passam a vida numa nação, vitimas dos acasos da reestruturação industrial, do down-sizing e da desvalorização social, com salários medíocres e com a precariedade como o seu destino [...] (NEAVE, 2001, p. 185).

O processo de globalização económica tem exercido uma influência negativa sobre a estabilidade de emprego e a capacidade negocial dos trabalhadores e das suas organizações. $\mathrm{O}$ direito ao emprego, até há bem pouco tempo um orgulhoso ornamento de muitas constituições nacionais e uma característica dominante do Estado providência está a ser substituído, de forma insidiosa mas persistente, pelo conceito de empregabilidade. Segundo Neave:

[...] a empregabilidade está muito longe de ser a mesma coisa que emprego. O emprego, podemos argumentar, deixou de ser responsabilidade dos governos. A responsabilidade foi transferida para o indivíduo. Compete ao indivíduo ... assumir a responsabilidade da sua empregabilidade frequentando cursos apropriados às suas competências, capacidades, ambições e por último - mas não menos importante - a ideia individual sobre onde podem dar-lhe vantagem no mercado (2002, p. 190).

Portanto, o processo de Bolonha pode ser interpretado como um novo passo no movimento neoliberal para diminuir a responsabilidade social do Estado (AMARAL; MAGALHÃES, 2004). Um primeiro ciclo de estudos, mais curto e menos dispendioso, dará aos estudantes um treino vocacional que lhes permitirá entrar no mercado de trabalho, passando depois a ser responsáveis por manterem a sua própria empregabilidade. O segundo ciclo de estudos (pós-graduação) será então mais evidentemente um bem privado e, como tal, devidamente pago pelos alunos sem novas exigências sobre os dinheiros públicos.

Pode argumentar-se que o discurso sobre a necessidade de aumentar a comparabilidade dos graus académicos corresponde, quer à necessidade de construir uma base sólida para a cidadania Europeia, quer à necessidade de os indivíduos se tornarem móveis no mercado de trabalho Europeu. De facto, Bolonha também pode interpretar-se como um mecanismo central de uma estratégia política no contexto da alteração da natureza do trabalho e do mercado de trabalho.

À medida que as 'carreiras' estão a ser substituídas por 'funções' (SENNETT, 2001) e a economia exige formas flexíveis de organização e recursos humanos flexíveis/ transferíveis, a questão da 'comparabilidade' torna-se central. Se para ser 'empregável' é preciso ser 'flexível', para ser flexível é preciso ter competências comparáveis.

De um modo curioso, o processo de Bolonha pode também ser visto à "luz do chamado deficit democrático das atuais instituições da Eurolândia” (NEAVE, 2002, 
p. 184). Tem havido urgência em apresentar os desenvolvimentos da saga de Bolonha sob o manto do consenso Europeu generalizado. Sucessivas conferências e seminários de validação foram cuidadosamente organizados para evitar ou diminuir as vozes discordantes, para produzir uma "celebração entre os fieis e os crentes" (Neave, 2002), mas “....seria bom saber que o consenso que sucessivas conferências e seus relatos dizem existir, também está presente em termos de 'aceitabilidade' para o 'país real' dos resultados operacionais - alterações na estrutura dos cursos, na sua duração, nos sistemas de creditação dos cursos e da sua modularização, entre outras coisas." Episódios recentes de discordância apresentados alto e em bom som, como os observados em Lisboa (2001) e Salamanca (2001), lançam dúvidas sérias sobre a "profundidade do consenso tão ardentemente desejado e tão regularmente documentado" (Neave, 2002, p. 187).

$\mathrm{O}$ processo de Bolonha entra agora numa nova e mais exigente fase. Se alguns dos princípios gerais (mobilidade, empregabilidade, comparabilidade, transparência) podem ser aceites de forma geral, uma coisa muito diversa será operacionalizar estes princípios políticos. Neave (2001) considera que: "O processo de Bolonha atingiu a fase em que os princípios começam a assumir forma institucional. $\mathrm{E}$ a forma institucional não anda muito longe da atribuição de mandatos. Contudo, aquele que fala de mandatos só está a um passo de levantar a questão fundamental do controlo e da coordenação" e Sursock afirma que:

O debate sobre a garantia da qualidade, tal como notou John Brennan, é na verdade sobre poder. É a questão de como a qualidade é definida e por quem. Poucas vezes são tidas em conta as questões que estão por trás da prestação de contas e da melhoria da qualidade. Porque se trata de uma questão de poder, os procedimentos de garantia da qualidade podem induzir distorções que não são necessariamente no melhor interesse de alunos, diplomados, empregadores e da sociedade em geral (2002, p. 2).

Portanto, não é surpreendente que ainda não tenha sido possível chegar a consenso sobre acreditação no processo de Bolonha. O que é talvez mais surpreendente é a natureza recorrente da doença da acreditação. Isto pode explicar-se pela metáfora epidemiológica de Levine (1998, p. 131-141): a presença de agentes infecciosos de uma estirpe particularmente resistente (consultores, peritos do processo de Bolonha, agentes de organizações que se dedicam à qualidade e/ou à acreditação...). Depois de cada tratamento médico - sob a forma de vozes institucionais discordantes - a doença desaparece aparentemente, para voltar a manifestar-se, de forma recorrente, passado algum tempo, em que o agente infeccioso está presente quer como a mesma espécie, quer sob a forma de alguma alteração genética. "Será que existem técnicas de prevenção que diminuam as probabilidades de contrair a doença? Haverá maneira de fortalecer a mente pública sobre educação para aumentar a sua resistência às infecções? ... algumas ideias sobre 'democracia forte” (BARBER, 1999) 
ou “sobre a sociedade civil potencial para tornar o 'corpo político da educação' mais robusto" (SURSOCK, 2002). Daí a necessidade de evitar a continuação da 'pseudo-validação' democrática das conferências e dos seminários de validação.

Deixem-me esclarecer que eu sou um Europeu convicto e não um jacobino disfarçado. Porém, eu sonho com uma Europa onde a inovação prevalecerá, onde a diversidade será protegida, e onde as ricas características culturais dos Estados membros serão defendidas. Eu imagino uma nova Renascença da Europa, uma Europa de l'esprit onde as universidades terão um papel fundamental, agora que o príncipe já não está presente para apoiar as artes. Excepto em pesadelos, não sonho com uma Europa de comissões e grupos de trabalho, de regras e regulamentos, de burocracias transnacionais. Será que o meu sonho se vai tornar realidade?

\section{The Bologna Process: from harmonization to tuning passing through the convergence}

\section{Abstract}

The students' mobility, the graduates employability and the course comparability appear as touchstone in the Bologna process. However, the students' mobility in Europe is restricted to a small percentage of the total amount of enrolled students and the liberal movement is reducing the government's social responsibility regarding their jobs. Notwithstanding the existence of governments which exalt the Bologna treaty, the process is now in a critical phase, risking to become a obstacle to innovation, to diversity and even to the rich characteristics of the Member States. In this work, are shown facts and presented arguments that highlight the vital moment that the Bologna process is passing by and the crude reality of difficult and hazards to the European's countries national's education systems.

Keywords: Higher Education. Bologna Process. European Area of Higher Education.

\section{Notas}

1 Para consulta de documentação sobre o processo de Bolonha recomendam-se dois endereços da internet: <http://www.unige.ch/eua/ da European Universities Association> e <http://www.esib.org/ da National Unions of Students in Europe>.

2 An EAIE comment: disponível em <http://www.esib.org/prague/eaie_comment_on_bologna.htm>.

3 The European Space for Higher Education, report presented by Dr. Kenneth Edwards, CRE President, on 19 June 1999 to the Ministers of Education. http://www.esib.org/prague/documents/meeting_report.htm

4 A CRE veio a transformar-se na EUA (European Universities Association) por fusão com a Confederação das Conferências de Reitores Europeus.

5 Veja-se, a propósito, a declaração conjunta dos estudantes feita por intermédio da ESIB e das Uniões Nacionais de Estudantes Europeus.

6 International Seminar on Credit Accumulation and Transfer Systems, Leiria, Portugal - 24/25 November, 2000, http://www.esib.org/prague/documents/bp-credits_ats.htm.

7 O projecto Tuning, a que dedicaremos alguns comentários, pretendia identificar perfis e competências 
comuns em áreas como Matemática, Geologia, Gestão, Serviços Educativos e História.

8 Conclusions and Recommendations of Seminar on Bachelor-Level Degrees, Helsinki, Finland, February 16-17, 2001, http:/www.esib.org/prague/documents/seminar-short_cycle.htm

9 Report and Recommendations of Transnational Education Project, Stephen Adam, University of Westminster, March 2001, Brussels, Confederation of European Union Rectors' Conferences.

${ }^{10}$ Towards Accreditation Schemes for Higher Education in Europe? Conclusions of the validation seminar, 8-10 February, Lisbon.

11 Veja-se, a propósito, o artigo "Degree Unity Sparks Friction” publicado por Rebecca Warden no Times Higher Education Supplement de 6 de Abril de 2001: "A acreditação foi outro tópico quente. Sami Kanaan, do secretariado da CRE, afirmou: algumas pessoas dizem que devemos encontrar mecanismos Europeus, outros dizem que não querem uma burocracia Europeia centralizada"

${ }^{12}$ Furthering the Bologna Process, Report to the Ministers of Education of the signatory countries, Pargue, May 2001, Rapporteur Pedro Lourtie.

${ }^{13}$ Message from the Salamanca Convention of Europen Higher Education Institutions-Shaping the Euro-pean Higher Education Area, http:/www.esib.org/prague/documents/EUA_message_for_prague.htm

${ }_{14}$ Joint Declaration on Higher Education and the General Agreement on Trade in Services, 28 September, 2001.

15 Letter from Bendt Bendtsen, the Minister for Economic and Business Affairs of Denmark, to Professor Sven Caspersen, President of IAUP, 1 August 2002, File 201-212-17.

\section{Referências}

ALDEMAN, C.; SILVER, H. Accreditation: the American experience, CNAA, London, 1990.

AMARAL, A. Higher education in the process of European integration, globalizing economies and mobility of students and staff. In: HUISMAN, J.; MAASSEN, P. (Ed.). Higher Education and the Nation State, London, Pergamon, 2001.

AMARAL, A.; MAGALHÃES, A. Epidemiology and the Bologna Saga. Higher Education, 48, p. $79-100,2004$.

ATTALI, J. Pour un Modèle Européen d'Enseignement Supérieur: Rapport de la Commission Présidée par Jacques Attali. Paris: Stock, 1998.

BARBLAN, A. "The Sorbonne Declaration - Follow-up and Implications: a personal view", paper presented at the XII Santander Group General Assembly, 17 April 1999.

BENDTSEN, B. Carta de resposta a pedido de informação da IAUP. Copenhaga, Ministro da Economia e Negócios da Dinamarca, 2002.

CARNEGIE FOUNDATION for the Advancement of Teaching (1987 revised edition), "A classification of institutions of higher education", Princeton, CFAT.

CRE. Acta de reunião do Conselho Directivo, Geneva. 2000.

DILL, D. et al. Accreditation and Academic Quality Assurance - Can We Get There From Here?, Change, September/October, p. 17-24. 1996.

EL-KHAWAS, E. Accreditation and Evaluation: Reciprocity and Exchange. Conference on Frameworks for European Quality Assessment of Higher Education, Copenhagen, 1993.

EUROPEAN COMMISSION. Memorando sobre o Ensino Superior na Comunidade Europeia, Bruxelas, 1991. 
IRDAC. Industrial Research and Development Advisory Committee. "Quality and Relevance: the Challenge to European Education”. IRDAC: Brussels, 1994.

LEVINE, B. “An Epidemic of Education Policy: (what) can we learn from each other? Comparative Education 34.2, 1998.

LOURTIE, P. Furthering the Bologna Process. Report to the Ministers of Education of the signatory countries. Prague: BFUG, 2001.

NEAVE, G. “Anything Goes: Or, How the Accommodation of Europe's Universities to European Integration integrates - an inspiring Number of Contradictions Tertiary Education and Management, v. 8, n. 3, p. 181-197, 2002.

SEMINAR ON BACHELOR-LEVEL DEGREES. Conclusions and recommendations of the seminar to the Prague higher 3ducation summit, The Bologna process, Helsinki, 16-17 Feb. 2001.

SENNETT, R. A corrosão do Carácter: as consequências pessoais do trabalho no novo capitalismo. Lisboa: Terramar, 2001.

SURSOCK, A. “Reflection from the higher education institutions' point of view: Accreditation and quality culture" paper presented at the international conference on accreditation and quality assurance Working on the European Dimension of Quality, Amsterdam, 12-13 March 2002.

TEICHLER, U., (1988), “Changing Patterns of the Higher Education System”, p. 31, London, Jessica Kingsley.

TROW, M. "Trust, markets and accountability in higher education: a comparative perspective". Higher Education Policy, v. 9, n. 4, p. 309-324, 1996.

TROW, M. Academic Reviews and the Culture of Excellence. Stockholm: Studies of Higher Education and Research, 1994.

TUNING. Tuning final conference, European Commission, Brussels, 31 may 2002.

Reference Points for the Design and Delivery of Degree Programmes in Chemistry, Bilbao: Universidad de Deusto. 2012a.

Reference Points for the Design and Delivery of Degree Programmes in Mathematics, Bilbao: Universidad de Deusto. 2012b.

VUGHT, F.A. "Higher education quality assessment in Europe: the next step." CRE-action. v. 96, n. 4, p. 61-83, 1991.

WEIGL, F. A. "E-Learning and the Trade-off Between Richness and Reach in Higher Education". Change, September-October, 2000, p. 10-15. 